\title{
An Achievement Prediction Model of Meaningful Learning, Motivation, and Cognitive on SPANI: Partial Least Square Analysis
}

\author{
Kuo-Kuang Fan, ${ }^{1}$ Chung-Ho Su, ${ }^{1,2}$ Shuh-Yeuan Deng, ${ }^{1}$ and Wei-Jhung Wang ${ }^{1}$ \\ ${ }^{1}$ Graduate School of Design, National Yunlin University of Science and Technology, 123 University Road, Section 3, Douliou, \\ Yunlin 64002, Taiwan \\ ${ }^{2}$ Department of Digital Content Application \& Management, Wenzao Ursuline University of Languages, 900 Min-Tzu 1st Road, \\ Sanming District, Kaohsiung 80793, Taiwan
}

Correspondence should be addressed to Kuo-Kuang Fan; fankk@yuntech.edu.tw

Received 7 September 2013; Accepted 10 October 2013

Academic Editor: Teen-Hang Meen

Copyright (c) 2013 Kuo-Kuang Fan et al. This is an open access article distributed under the Creative Commons Attribution License, which permits unrestricted use, distribution, and reproduction in any medium, provided the original work is properly cited.

\begin{abstract}
This paper employed an SPANI (Shooting Pose Adjustment with Nature Interactions) learning system with achievement prediction model of meaningful learning. Motivation, cognitive, and PLS (Partial Least Square) method was used to analyze the results. Proposed model is focused on information and communication technology teaching mode, meaningful learning, learning motivation, cognitive load, and learning achievement. Theories of SPANI achievement prediction model investigated the learner's degree of meaningful learning, learning motivation, cognitive loading, and learning achievement (Huang et al. 2012, Credé and Phillips 2011, Deleeuw and Mayer 2008, and Peterson et al. 2010). Questionnaire and systems tests were used with 107 valid samples in the samples' record to conduct narrative statistics, inspection of reliability and validity, and PLS of Structural Equation Modeling (SEM). The results show that the developing system is very helpful to learner's learning motivation and learning achievement. And learner's learning motivation, which influences the degree of the cognitive load and learning achievement, has a high relationship. It means, the designers of teaching materials can start with digital content to improve learning motivation and also handle the two important parts which are learning strategy and learning motivation. It can be very helpful in improving teaching quality.
\end{abstract}

\section{Introduction}

The use of technology covers a wide range of fields, and it includes the field of education. Technology can improve the quality of education. Digital technology has made many changes in teaching materials and aids and has become the essence of technological change in learning. To make use of the content found on the internet for teaching in synchronous or asynchronous ways, digital tools have been applied widely in recent years. Which kind of circumstances requires the use of the information and communication technology (ICT)? We should consider the most fundamental needs and goals of learners and then determine the appropriate teaching strategies and tools, including the media and even checklists of the learning results of students. Maleki et al. [1] developed the ICT teaching model to investigate the students' learning in the area of information processing capability and their study pointed out that compared to the use of information and communication technology in a teaching mode, the experimental group had significant differences in learning absorption compared to the control group in this study. Maleki et al. [1] strongly recommended using ICT in teaching and claimed that it can improve student learning absorption and teaching quality.

Information technology is widely believed to be useful for increasing students' learning. However, students vary and the learning outcomes are not all the same. After all, each learners' motivation or cognitive load has differences, as was found in Ausubel and Robinson's [2] study which considered the value of learning new concepts through meaningful learning. The biggest factor which affects learning is the cognitive structure state. Kalyuga et al. [3] also mentioned many studies 
that were based on the instructional design to reduce the extraneous cognitive load and give the appropriate cognitive load to assist teaching activities.

In addition to checking the learner's cognitive load, we considered researching whether the design of digital materials can enhance learners' motivation or not. Pintrich et al. [4] developed a measurement tool termed Motivated Strategies for Learning Questionnaire (MSLQ) that can be used to investigate learners' cognition for participation in learning tasks, motivation, and the degree of participation in different learning tasks under different learning strategies.

Similarly, how to test learners' absorption, how to prove that the things we learned have been absorbed, and related research also examined how to test the learner's learning achievement [5-8]. Purdie and Hattie [6] think that learning needs peers to communicate with each other. Also though knowledge has been arranged and absorbed, it still needs to be spoken out to be completely understood. Through the learners' narrations, researchers can examine whether the knowledge has been digested. Thus, if a learner can explain what they have learned to another, then that indicates that the learning has been successful.

For these above reasons, this study is based on the above criteria, and we design a digital program to teach correct shooting postures to serve as the learning material. Then, we use SPANI to analyze the learners' learning motivation, cognitive load, and learning achievements. This is the main motivation of this study.

Below, we will discuss some articles that are related to history, biological exploration, language learning, and geometry. We also examine basketball shooting posture or movements related to basketball. However, the amount of learning attitude research about basketball posture is mostly from overseas and their little research available domestically in this area.

In this study, we focus on meaningful learning, learning motivation, cognitive loading, and learning achievements as the theoretical basis. We discuss the relation between and impact of meaningful learning, learning motivation, the cognitive load, and learning achievements from the digital shooting posture correction learning materials of SPANI. The main purposes are summarized as follows.

(i) Investigate the learners' association towards learning strategies, learning motivation, and learning achievements of SPANI.

(ii) Investigate the learners' association towards learning strategies, the cognitive load, and learning achievements of SPANI.

(iii) Investigate the learners' association towards learning motivation, and the cognitive load of SPANI.

\section{Related Work}

2.1. Information and Communication Technology Teaching Mode. Currently, the applications of Internet are being used in many fields, including the field of education. Nowadays, teachers not only can upload teaching materials online, but can even use online teaching programs to instruct students. Through this way of learning, students can learn anytime and anywhere, if they want. It also helps students learn efficiently. Students and teachers should assess their needs and goals as the first consideration. Then they need to decide which teaching materials are most appropriate. Maleki et al. [1] mentioned that information explores the research of student's abilities in dealing with things and learning information which in experimental group of absorbing learning effects has noticeable differences within investigated group of absorbing learning effects. Furthermore, Maleki et al. [1] strongly suggested that people use it in teaching; it can improve students' efficiency of learning and improve the quality of teaching.

2.2. Meaningful Reception Learning. Meaningful reception learning can also be called meaningful learning. In 1963, Ausubel [9] interpreted what the meaning of meaningful reception learning is, based on his investigation about learning and consciousness. He states that encouraging students to make connections with the teaching material they have been taught along with things they have already known is what meaningful learning is all about. Ausubel and Robinson [2] indicated that via the idea of the meaningful reception learning students can achieve greater efficiency in learning because people have basic consciousness about the knowledge in this type of learning. They emphasized that the knowledge of teaching should use key concepts as the central idea and recommends teachers to give students suggestions if they raise the idea about organizing content $[2,9,10]$.

2.3. Cognitive Load Theory. According to Sweller [11], there are three sources for the cognitive load as follows. Intrinsic cognitive load from the structure and complexity of the materials. Thus, depending on the complexity of the teaching materials or components in interactive projects, it takes learners different amounts of time to learn memory resources and understand the amount of information in textbooks [12]. Extraneous cognitive load is the source of the cognitive load when delivering textbook information or presenting it in a way to let learners spend learning memory resources in the teaching activities. Germane cognitive load is based on the load when learners understand how to deal with materials $[13,14]$.

The extraneous cognitive load and the germane cognitive load are usually used in instructional design textbooks when taking how to improve teaching effectiveness and efficiency into consideration. In many studies, these are based on the instructional designing to reduce the extraneous cognitive load and provide appropriate sources to assist in teaching activities [3].

The aim of instructional design is to see whether the degree of the cognitive load is acceptable to the learner or not. The intrinsic cognitive load depends on learners having prior knowledge and learning memory resources. In instructional design, it is unable to control these factors, but the learners can achieve the appropriate level of the cognitive load by the extraneous cognitive and the germane cognitive load. 
2.4. Motivated Strategies for Learning Questionnaire. Learners may perform because of motivation, cognition, and learning behavior to select multiple types of academic tasks across different courses (e.g., attend seminars in major courses or select a general education curriculum) or choose different types of learning tasks in the same course (such as prepare a multiple-choice exam or write a glossary report). Every learner in the learning process needs to have self-learning process of situational tests [15]. Empirical research indicates that the self-learning processes and learning mechanisms need a variety of information about the structure of selfmeasurement, and these must be valid and also a reliable measurement of autonomous learning. Pintrich and colleagues [4] developed a detection method called Motivated Strategies for Learning Questionnaire (MSLQ). The incentive motivation questionnaire is used to investigate learners' cognitive involvement in learning task, and the motivation and degree of participation for learning tasks in different learning strategies.

The learning motivation scale contains 15 dimensions and totally has 81 items in the questionnaire. It is used to investigate whether the students have strong motivation to participate in courses and test learning strategies. The seven point Likert scale is used as the measurement tool. Among the 81 questions, there are eight negative worded items. There are 31 questions. Among these 31 questions, there are six measurement scales to investigate students' oriented motivation in the academic curriculum. These six measurement scales are based on three motivation theories, such as the value component, expectancy component, and affection component [16].

2.5. Learning Achievements. The basis of learning achievement originated from the investigation made by Säljö [17]. In the investigation of Säljö's [17] research, Säljö examined every age group of people and related the meaning of learning to them. Säljö did his investigation to find 5 aspects of learning achievements and has six subjects [18] to discuss the perspective, the learner's process of learning, and finally how learners prove they really understand the knowledge they have learned. The relative investigation also proves the six aspects of learning achievement [5-8].

\section{Research Framework}

According to Ausubel et al. [10] who proposed the meaningful learning theory, this study will use it as the learning framework combined with Sweller's [19] cognitive load theory. We use Pintrich's et al. [4] measurement tools, which confer the learning conditions which learners have after having used these digital learning materials and uses. Then, we use assessing student's conception of learning [6] as a learner learning achievement for checking and evaluation. This research framework is shown in Figure 1.

3.1. Research Hypotheses. According to the related research, this study proposes the following assumptions.

(H1) Using proper learning strategies to enhance learning motivation has significant influences.

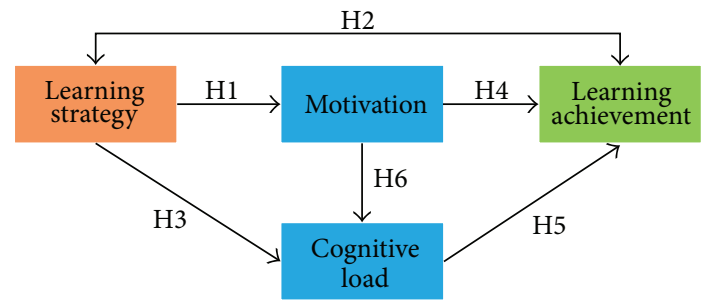

FIGURE 1: Research framework.

(H2) Using proper learning strategies to enhance learning achievements has significant influences.

(H3) Using proper learning strategies to enhance the cognitive load has significant inverse influences.

(H4) Using proper learning motivation to enhance learning achievements has a significant positive relationship.

(H5) The cognitive load has a significant inverse relationship with learning achievement.

(H6) Learning motivation has a significant relationship with the degree of the cognitive load process ability.

3.2. Research Subjects and Data. This study focuses on the users of digital learning shooting posture correction materials which were developed specifically for this research. It targets college students as the research subjects to explore the research related to meaningful degree of learning, motivation of learning, cognitive load, effects of learning, and learning achievements when using a digitally designed lesson program to instruct the correct posture while shooting. This study aimed to correct college students' shooting posture for different poses, including the following: standby pose, aim pose, release pose, and shooting pose. This study used judgmental sampling. In order to reduce the incidence of invalid questionnaires, the researcher explained each point or problem that needed any explanation as they came up.

\section{System Framework and Description}

The system developed in this study uses the Nature Interaction of Shooting Pose Adjustment Program that is used by Nature Interaction (SPANI). It includes a shooting position tutorial and a test for the correct basketball shooting posture. Shooting position tests of shooting postures are designed for both right-handed and left-handed people. SPANI system framework is shown in Figure 2 above.

4.1. System Design. The SPANI system is built on the game engine Unity 3.4.1. We need a database for the information storage of the data we collect on the subjects' shooting posture. This study used C\# and JavaScript languages to implement the system requirements. For the hardware identification detection, we used Asus Xtion Pro. Next, we will introduce the processes of the system, the database, and the system interface. 


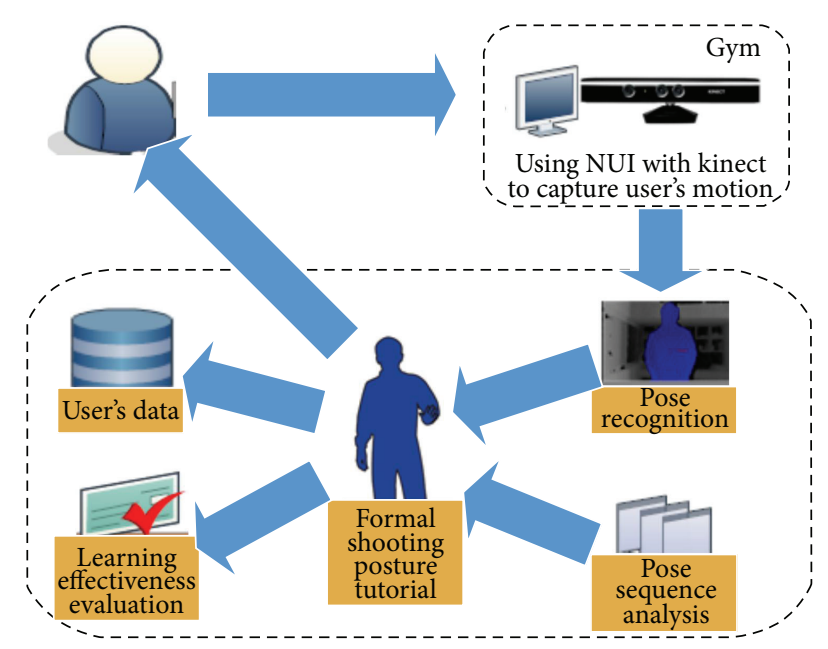

Figure 2: SPANI system framework.

We used the local database using MySQL Workbench 5.2 CE, the Unity linked database, and also C\# (C-Sharp) language to access the language to load the information.

Images can be divided into foreground and background images, and because of the depth numerical value, a lot of depth sensors define the optimum sensing range to be 0.8 meters to 3.5 meters and the effective angle of depth camera has a $70^{\circ}$ angle. The depth sensors have detected the skeleton set of depth numerical values and imported the 3D models to obtain the skeleton information and then they have combined them together. The 3D data can orientate each user's joint depth in an action and then turn that image into the threedimensional coordinates $(X, Y$, and $Z$ ). The system uses the depth camera to detect when a motion is not correct during the activity and produces three dimensional coordinates. This is the character control. The $3 \mathrm{D}$ models in the system are the system which catches a user's three-dimensional coordinate interfaces when he or she is doing the action. Meanwhile, the action's feedback of the 3D model is from the user. In other words, as a user's action changes, the actions of the threedimensional model will change too.

4.2. Character Control. Use the OpenNI's software development kit (SDK) [20] that was provided specifically for the game engine used in Unity 3D. The software development kit provides the skeleton information correspondence and then makes the 3D modeling software MAYA and joint information including Joint, Inverse Kinematics, and Forward Kinematics into the game engine. Also, the above makes the joint information correspond with the joint information of the software development kit and completes the model and links with OpenNI.

4.3. System Operational Process. According to the basketball shooting position key actions which were mentioned before, they are the standard actions that this research has defined related to basketball free throws. These above mentioned four actions are listed as the key actions, and the name label and

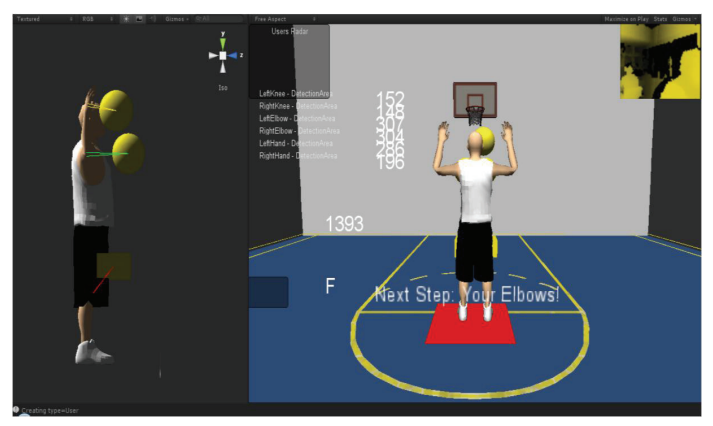

Figure 3: Material demonstration.

definitions are used to obtain the three dimensional coordinates' values of the fuzzy set. The position identification procedure pictured in Figure 4 illustrates how this process operates. The Nature Interaction Device utilizes OpenNI to receive preliminary skeleton frame information and orientates each skeleton coordinate with the game engine, and it uses the Trapezoid membership function to judge the standard area. With user's key actions, it will start to check whether the coordinates are in the area of the Trapezoid membership function or not. If it identifies user's actions that have been successful, then it will record user's key actions into the motion sequence that the user has created; if it failed, it will record the results into the motion sequence that the user has created. According to whether the user's key actions are identical to the key motion sequence orders and actions, it will continue to record the user's key actions until all have been completed. Material demonstration is shown in Figure 3.

4.4. Design of Teaching Activities. This section will introduce the design of the teaching activities in this investigation. The investigation is mainly designed for assisting users through interactive instruction to correct the wrong posture when shooting basketballs. Students are not only taking in the knowledge the teacher has taught in class, but are also learning actively. The passive way of learning is not an effective way for students to absorb knowledge or the so called bias or incomplete results. This study hopes to design a studentoriented teaching environment. The previous chapter has introduced the system ability to detect specific joints and detective area. The operating of the study can be accomplished by the depth camera's depth views, which instructs users when their movements are incorrect and when they are correct. In conclusion, users can learn through a physically interactive method to assist learning of the correct posture to shoot a basket.

The teaching activity environment has been developed in an indoor area that provides a large space.

The investigation used the high school physical education and information technology instructions from the Ministry of Education in Taiwan [21] as a reference material. The investigation particularly refers to basketball and is mainly designed to instruct the correct posture to shoot a basket. The design of the teaching activity in the investigation has been 


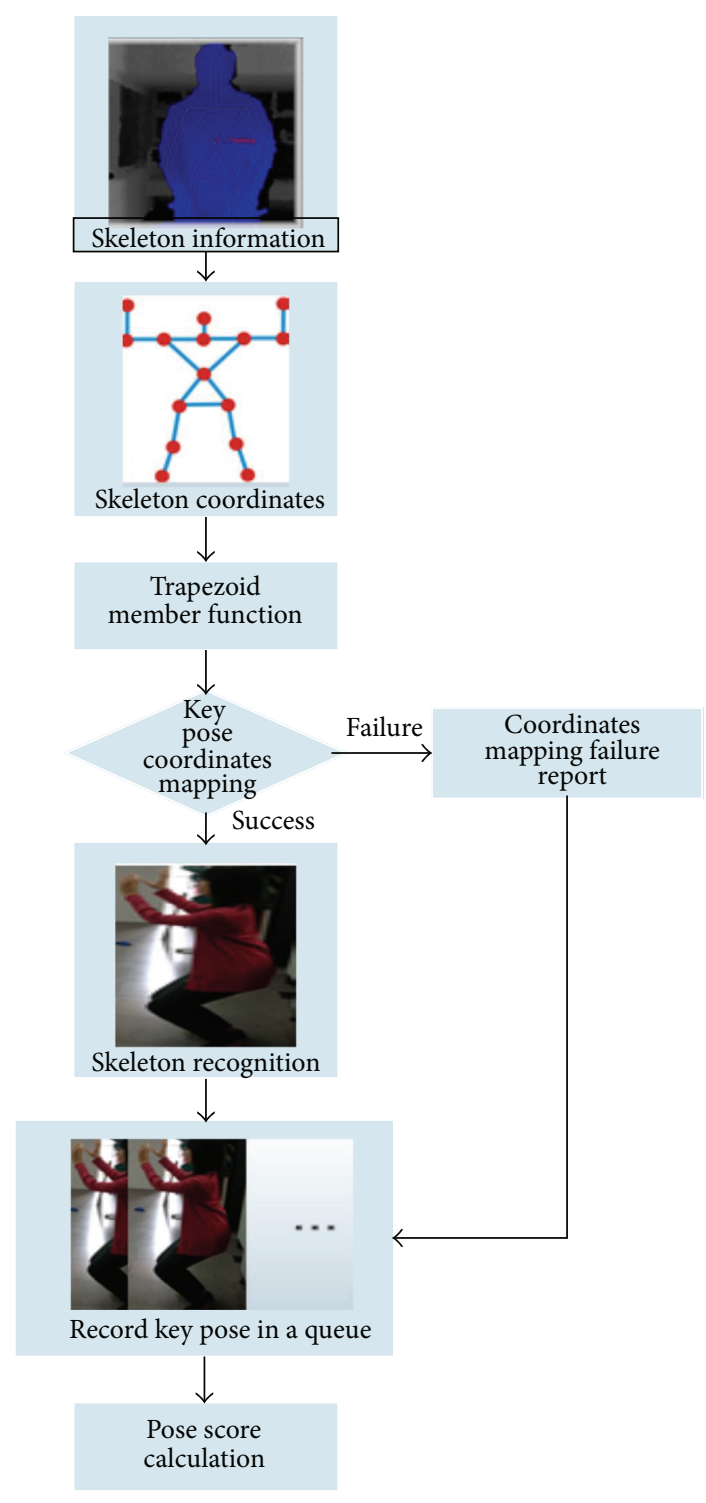

FIGURE 4: Position identification procedure.

divided into 4 scenes. In the teaching activity, users learn through interacting with a depth camera and with a motionsensing interactive software to carry on the teaching of the correct posture before shooting the basket. At the same time, users can learn through interactive motion sensing to manipulate the character in the material of shooting posture. In the four levels, the study will design teaching goals to initiate the users to accomplish various tasks and how to be successful in learning to shoot a basket with the correct posture. There are four kinds of instructional activities in total. Each of teaching activity has its teaching goal, a way to do the interaction, and finally a way to teach the acquisition of the skills.

Scene 1. Standby pose instructs users to position their joints in the detection area as specified by the system.

This scene of teaching activities is designed to assist users in having the correct posture for the shooting position as a Standby pose. Users are viewed through the depth camera and have interaction with the virtual characters, and then the users need to adjust their own joints to conform to the view shown in Scene 1, which shows the hand at the waist in the detection area and in front of the knee in the detection area. When users make their posture conform to the instructions, as shown in Scene 1, the system will give them feedback. Users can learn through the feedback and then adjust their joint position again. The essential tips of this program are that it stabilizes breathing and emotions before shooting, and after stabilizing these, the knee are bent slightly in the instructions. This is to instruct users about the power of bent knees to assist the arms in shooting a basketball.

Scene 2. Aim pose instructs users to adjust joints based on the system's specified instructions and places them in the detection area.

This part of the instruction is designed to assist users to prepare certain movements prior to attempting to shoot a basketball. The user interacts with the virtual character in teaching material through the depth camera. The users need to adjust the position of their joints at the same time, in accordance with the instructions presented in Scene 2. The hands need to be in the detection area, in order to accord with the definition in Scene 2 at hand detection in the chest area. The height between the chest and stomach is elbow detection area. The knee detection area is in front of knee. When users do the posture and meet the demands presented in Scene 2, the system will provide feedback. Moreover, the users can readjust their joint positions based on the feedback. The important part of this action is using the eyes to focus on the rim and prepare to shoot a basket. Scrunch up the joints of the elbows, and tighten the angle of the elbows to less than $90^{\circ}$ degrees. The reason why users are instructed to tighten the angle of the elbows to less than $90^{\circ}$ degrees is because users can shoot the ball with a shorter radius and even make a more stable and effort-saving shot.

Scene 3. Shooting pose instructs users to position their joints in the detection area as specified by the system.

This part of the instruction is designed to assist users to prepare the holding movement. The users position themselves based on the virtual people in the teaching material, according to the depth view provided by the depth camera. The users simultaneously need to adjust the position of their joints, in accordance with the instructions provided in Scene 3 in the detection area, which shows where the hands and head are to be. It also shows the correct height between the shoulders and elbows in the detection area, and the position of the knees is in front of knee. When users do the movements according to the instruction in Scene 3, the system will provide feedback. Moreover, the users can readjust their joints based on this feedback. The important point of this movement is the stretching out of the fingers and holding the ball in the correct way. Instead of using the palm to hold the ball, users should hold the ball with their fingers to control the direction where it will go.

Scene 4. Release pose instructs users to touch the detection block that is specified by the system. 
This part of the instructions is designed to assist the users with the correct movements as shooting. The users interact with the virtual character in the teaching material through the depth view provided by the depth camera. The users need to simultaneously adjust the positions of their joints to be in accordance with the instructions provided in Scene 4 . When users do the movements correctly according the instructions in Scene 4, the system will provide feedback. Moreover, the users can readjust the positions of their joints according to this feedback. The important part of this movement is to instruct users to properly let the ball rub against their fingertips as it is released, giving the ball backspin, which will increase the chances of successfully making the shot.

\section{Outcome Analysis of the Investigation}

5.1. Analysis of Pretesting. After completing the design of the questionnaire, there were 34 questions. Furthermore, the questionnaire was tested for validity prior to being used for collecting data. Before conducting the pretesting, the questionnaires needed to be processed through the SPANI system which in this investigation has been designed to instruct students in the proper posture for shooting a basketball. The pretest questionnaires were filled out and returned prior to the actual testing. The administration of the pretesting questionnaires was done with the assistance of other college students. These students, generously, gave their time to assist me with the conduction of the investigation. It took 17 days to finish the pretesting. All the 51 questionnaires were collected on the spot. In order to make sure of the reliability of the questionnaires, I, immediately, put all the questionnaires into SPSS 21.0 system to do the reliability analysis. The measurement of reliability is through Cronbach's $\alpha$ value as the basis. Preadvance deleted out the questions that can improve the Cronbach's $\alpha$ value. Among the meaningful learning, learning motivations, cognitive load, and learning achievement can reach Cronbach's $\alpha$ value which is larger than 0.7. However, the total Cronbach's $\alpha$ value was up to 0.935 , and it indicates that no matter whether the Cronbach's $\alpha$ value was only in one aspect for the questions or was for all the aspects, there would be high correlation.

5.2. Analysis Sample of Structure. The questionnaire of this investigation is mainly designed for college students as the research target. This investigation adopts judgmental sampling to take the samples. The distribution of questionnaires was done with the help of my college friend. In each time the experiment was to be done, I describe the purpose of research, introduce the name of the system, make an introduction of the system and finally demonstrate the operation of the system to the research participants. After the users perform the tasks specified by the program, the researcher next would explain how to fill out the questionnaire.

The questionnaires were distributed on the spot. 129 questionnaires were handed out and 129 were collected.

One questionnaire was later omitted because of a missing value, and also 21 questionnaires were later omitted because the answers were not in accord with the previous answers they
TABLE 1: Frequencies and percentage of observed variables.

\begin{tabular}{llcc}
\hline Variable & Level & Frequency & Percentage \\
\hline \multirow{2}{*}{ Gender } & Female & 61 & $57 \%$ \\
& Male & 46 & $43 \%$ \\
Habit of exercise & $\begin{array}{l}\text { Do not have habit } \\
\text { of exercise }\end{array}$ & 34 & $31.8 \%$ \\
& $\begin{array}{l}\text { Have the habit } \\
\text { of exercise }\end{array}$ & 73 & $68.2 \%$ \\
& 0 times & 16 & $14.9 \%$ \\
The times of & One to two times & 66 & $61.7 \%$ \\
exercise & Three to four times & 23 & $21.5 \%$ \\
in every week & Five to six times & 2 & $1.9 \%$ \\
& more than seven & 0 & $0 \%$ \\
& times & 45 & $42.1 \%$ \\
Each exercise & 30 minutes & 47 & $43.9 \%$ \\
time & $31-60$ minutes & 10 & $9.3 \%$ \\
& 61-90 minutes & 5 & $4.7 \%$ \\
\hline
\end{tabular}

TABLE 2: Latent variable correlations.

\begin{tabular}{lcccc}
\hline Variables & CL & LA & LM & ML \\
\hline Cognitive load (CL) & 0.73 & & & \\
Learning achieve (LA) & 0.15 & 0.76 & & \\
Learning motivation (LM) & 0.17 & 0.71 & 0.82 & \\
Meaningful learning (ML) & -0.029 & 0.61 & 0.71 & 0.73 \\
\hline
\end{tabular}

had filled in. Finally, there were 107 valid questionnaires, with a percentage of $82.9 \%$.

There are 107 valid samples of the questionnaire. The data from these questionnaires were submitted to personal profile analysis and the following categories were included: gender, exercise habits, weekly exercise frequency, and total time spent exercising each session. Table 1 illustrates the frequencies and percentage of observed variables.

5.3. A Measurement Model of Evaluation. In structural equation modeling (SEM) analysis, the SEM analysis is divided into the measurement model and the structural model. And PLS analysis procedure is divided into two stages: the first stage tests for measurement reliability and validity test analysis and the second stage of the model measurement is a path coefficient to estimate the explanatory power of the model prediction and verification.

5.3.1. Reliability Analysis. PLS measurement models were tested. The terms of reliability included individual items reliability and internal consistency to test the reliability of the sample data. In some facets of internal consistency, the reliability and Cronbach's $\alpha$ composition values have a similar index measurement. The reliability, we suggested, is for values greater than 0.7 degrees [22-25].

Table 4 illustrates that the composite reliability of various research aspects ranged from 0.8521 to 0.9505 in this study, where the composite reliability was higher than the 0.7 
TABle 3: Hypotheses table.

\begin{tabular}{ll}
\hline The content of the hypotheses & Result \\
\hline H1: Using proper learning strategies to enhance learning motivation has significant influences. & Significant \\
H2: Using proper learning strategies to enhance learning achievements has significant influences. & Significant \\
H3: Using proper learning strategies to enhance the cognitive load has significant inverse influences. & Significant \\
H4: Using proper learning motivation to enhance learning achievements has a significant positive relationship. & Significant \\
H5: The cognitive load has a significant inverse relationship with learning achievement. & Not significant \\
H6: Learning motivation has a significant relationship with the degree of the cognitive load process ability. & Significant \\
\hline
\end{tabular}

TABLE 4: Dimension tables of reliability and validity.

\begin{tabular}{|c|c|c|c|c|c|c|c|}
\hline Aspect name & Measurable variables & Q.NO & Avg & $t$-value & $\mathrm{CR}$ & AVE & Cronbach's $\alpha$ \\
\hline \multirow{8}{*}{ Meaningful learning } & \multirow{3}{*}{ Active } & MeAct2 & 5.31 & 4.883 & \multirow{8}{*}{0.91} & \multirow{8}{*}{0.57} & \multirow{8}{*}{0.89} \\
\hline & & MeAct3 & 5.35 & 8.335 & & & \\
\hline & & MeAul & 5.27 & 6.808 & & & \\
\hline & Authentic & MeAu2 & 4.92 & 6.959 & & & \\
\hline & 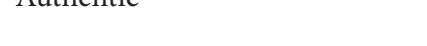 & MeAu3 & 5.27 & 7.514 & & & \\
\hline & \multirow{3}{*}{ Constructive } & MeCon1 & 5.53 & 6.500 & & & \\
\hline & & MeCon2 & 5.37 & 9.526 & & & \\
\hline & & MeCon3 & 5.63 & 5.779 & & & \\
\hline \multirow{3}{*}{ Learning motivation } & Control beliefs & MoCB1 & 5.71 & 3.881 & \multirow{3}{*}{0.85} & \multirow{3}{*}{0.66} & \multirow{4}{*}{0.74} \\
\hline & Intrinsic goal orientation & MoIG1 & 5.37 & 7.250 & & & \\
\hline & Task value & MoTV1 & 5.45 & 5.773 & & & \\
\hline \multirow{3}{*}{ Cognitive load } & Difficulty rating & $\operatorname{Cog} \mathrm{D} 1$ & 2.47 & 7.529 & \multirow{3}{*}{0.86} & \multirow{3}{*}{0.68} & \\
\hline & Effort rating & $\operatorname{Cog} \mathrm{E} 1$ & 3.55 & 10.713 & & & \multirow[t]{2}{*}{0.78} \\
\hline & Response time to secondary task & $\operatorname{Cog} R 1$ & 4.00 & 5.073 & & & \\
\hline \multirow{10}{*}{ Learning achievement } & \multirow{2}{*}{ Understanding } & AchU1 & 5.80 & 5.880 & \multirow{10}{*}{0.95} & \multirow{10}{*}{0.66} & \multirow{10}{*}{0.94} \\
\hline & & AchU4 & 5.14 & 7.860 & & & \\
\hline & \multirow{4}{*}{ Personal changes } & AchPC1 & 5.49 & 5.644 & & & \\
\hline & & AchPC2 & 5.78 & 10.614 & & & \\
\hline & & AchPC3 & 5.82 & 9.899 & & & \\
\hline & & AchPC4 & 5.80 & 8.490 & & & \\
\hline & \multirow{4}{*}{ Gain information } & AchGI1 & 5.78 & 5.392 & & & \\
\hline & & AchGI2 & 5.88 & 9.715 & & & \\
\hline & & AchGI3 & 5.86 & 8.490 & & & \\
\hline & & AchGI4 & 5.86 & 6.325 & & & \\
\hline
\end{tabular}

threshold for each dimension of Cronbach's $\alpha$, and are greater than 0.7 , which means that every dimension has good reliability $[24,26,27]$.

5.3.2. Convergent Validity. Convergent validity refers to the same aspect of the measurement results with a high correlation (measurements of multiple variables are the same aspects as measured degree of compliance). Convergent validity can be tested through composite reliability (CR) and average variance extracted (AVE). According to the recommendation of Fornell and Larcker [23] and Hair et al. [26], the composite reliability should be above 0.7 , and the average of Average Variance Extracted, AVE, should be greater than 0.5 shown in Table 2. It represents at least the $50 \%$ level for the explanation as the reference index of convergent validity. The composite reliability of the four aspects in this study ranged from 0.8521 to 0.9505 ; the average variance extracted amount ranged from
0.5754 to 0.6805 . All reached the threshold. Hence, these study constructs have convergent validity.

5.4. Structured Model Evaluation. Structured Model Evaluation is utilized to estimate path coefficients of research hypothesis which is significance or not. The purpose is to explain the relationship between dependent variables and independent variables. Structural model analysis is also used to view the independent variables, which affect the dependent variable for explanatory power $\left(R^{2}\right)$ and the explanatory power of the model $[23,26,28,29]$.

In this study, the structural model and the relationship between the various aspects of the path coefficients and test results are shown in Tables 5 and 6 and Figure 5. There are motivations, cognitive loads, and learning achievements in the actual usage behavior. The total variance $R^{2}$ values for motivation, cognitive load, and learning achievement were 
TABLE 5: Effective results of latent variables.

\begin{tabular}{|c|c|c|c|c|c|c|c|c|c|}
\hline & \multicolumn{3}{|c|}{ Learning motivation } & \multicolumn{3}{|c|}{ Cognitive load } & \multicolumn{3}{|c|}{ Learning achievements } \\
\hline & Direct & Indirect & Total & Direct & Indirect & Total & Direct & Indirect & Total \\
\hline Meaningful learning & 0.717 & - & 0.717 & -0.320 & 0.291 & -0.029 & 0.235 & 0.386 & 0.621 \\
\hline Learning motivation & - & - & - & 0.406 & - & 0.406 & 0.535 & 0.029 & 0.564 \\
\hline Cognitive load & - & - & - & - & - & - & 0.071 & - & 0.071 \\
\hline
\end{tabular}

TABLE 6: Path coefficients analysis result.

\begin{tabular}{|c|c|c|c|c|}
\hline Hypothesis & Path & Standardized estimates & Standard error & $T$ value \\
\hline H1 & Meaningful learning $\rightarrow$ learning motivation & 0.717 & 0.0585 & $12.266^{* *}$ \\
\hline $\mathrm{H} 2$ & Meaningful learning $\rightarrow$ learning achievements & 0.235 & 0.1147 & $2.048^{*}$ \\
\hline $\mathrm{H} 3$ & Meaningful learning $\rightarrow$ cognitive load & -0.320 & 0.143 & $2.241^{*}$ \\
\hline $\mathrm{H} 4$ & Learning motivation $\rightarrow$ learning achievement & 0.535 & 0.1326 & $4.036^{* *}$ \\
\hline H5 & Cognitive load theory $\rightarrow$ learning achievements & 0.071 & 0.0679 & $1.043^{\text {N.S. }}$ \\
\hline H6 & Learning motivation $\rightarrow$ cognitive load theory & 0.406 & 0.1473 & $2.755^{* *}$ \\
\hline
\end{tabular}

${ }^{*} P$ values reach the significant standard which is $0.05(t \geq 1.6602)$; ${ }^{* *} P$ values reach the significant standard which is $0.01(t \geq 2.3642)$.

N.S. (not significant) $P$ value does not reach the 0.05 significant standard $(T$ value $<1.6602)$.

$51.5 \%, 8.1 \%$, and $53.9 \%$ of the variance, respectively. Through the structural model analysis of PLS, the results showed the following for the system developed for the research: the users' degree of meaningful learning has a significant positive influence on SPANI (Shooting Pose Adjustment with Nature Interactions) learning motivation $(\beta=0.717, P<0.01)$; that is, SPANI has a high degree of meaningful learning for learners. Moreover, SPANI users have higher learning motivation.

It also found that the users' degree of meaningful learning has a significant positive influence on SPANI learning achievement $(\beta=0.235, P<0.05)$. That is, SPANI has a high degree of meaningful learning for learners, and those using SPANI had a higher level of academic achievement.

\section{Conclusion and Discussion}

This research mainly targets college students as the research subjects. We have investigated college students' behaviors and attitudes of association towards the degree of meaningful learning, learning motivation, cognitive, and learning achievements after using the digital shooting posture correction materials SPANI. Through the information analysis, statistics verification, and investigation, we have proposed hypotheses for this research which can be found in Table 3 and which explain these hypotheses one by one.

6.1. Research Conclusion and Findings. This research mainly targets college students as the research subjects. We have investigated college students' behaviors and attitudes of association towards the degree of meaningful learning, learning motivation, and cognitive and and learning achievements after using the digital shooting posture correction materials SPANI.

Subjects' Learning Motivation Positively Influenced by SPANI. The research results show that when SPANI subjects accept meaningful learning use of learning strategies, it has positive influence on subjects' learning motivation. Hence, SPANI subjects think that to accept SPANI learning strategies is useful to increase learning motivation. Therefore, the research results of Credé and Phillips [15] are supported.

Subjects' Academic Achievements Positively Influenced by SPANI. The research results show that when SPANI subjects accept meaningful learning use of learning strategies, subjects learning achievements will become higher. Hence, SPANI subjects think that to accept SPANI learning strategies is useful to increase learning achievements. Therefore, this research supports the findings of Chang and Ley [30].

Subjects' Cognitive Loads Have Been Negatively Influenced by Using SPANI. The research results show that when SPANI subjects accept meaningful learning use of learning strategies, subject's cognitive load will become lower. Hence, SPANI subjects think that to accept SPANI learning strategies is useful to decrease cognitive load. Our research findings conform with those of Michael Pressley [31], Chang and Ley [30], Binet and Simon [32], and Laidra et al. [33].

SPANI Subjects' Learning Motivation Has a Significantly Positive Relationship with Learning Achievement. The research results show that when SPANI subjects learning motivation increases while using SPANI, their learning achievements will also improve. This point supports the research results of Credé and Phillips [15], Duncan and McKeachie [16], and McClure et al. [34].

SPANI Subjects' Cognitive Loads Do Not Have Significantly Negative Relationship with Learning Achievement. The research results show that SPANI subjects' cognitive load has no significant negative influence on learning achievement when using SPANI. It means that SPANI subjects' cognitive 


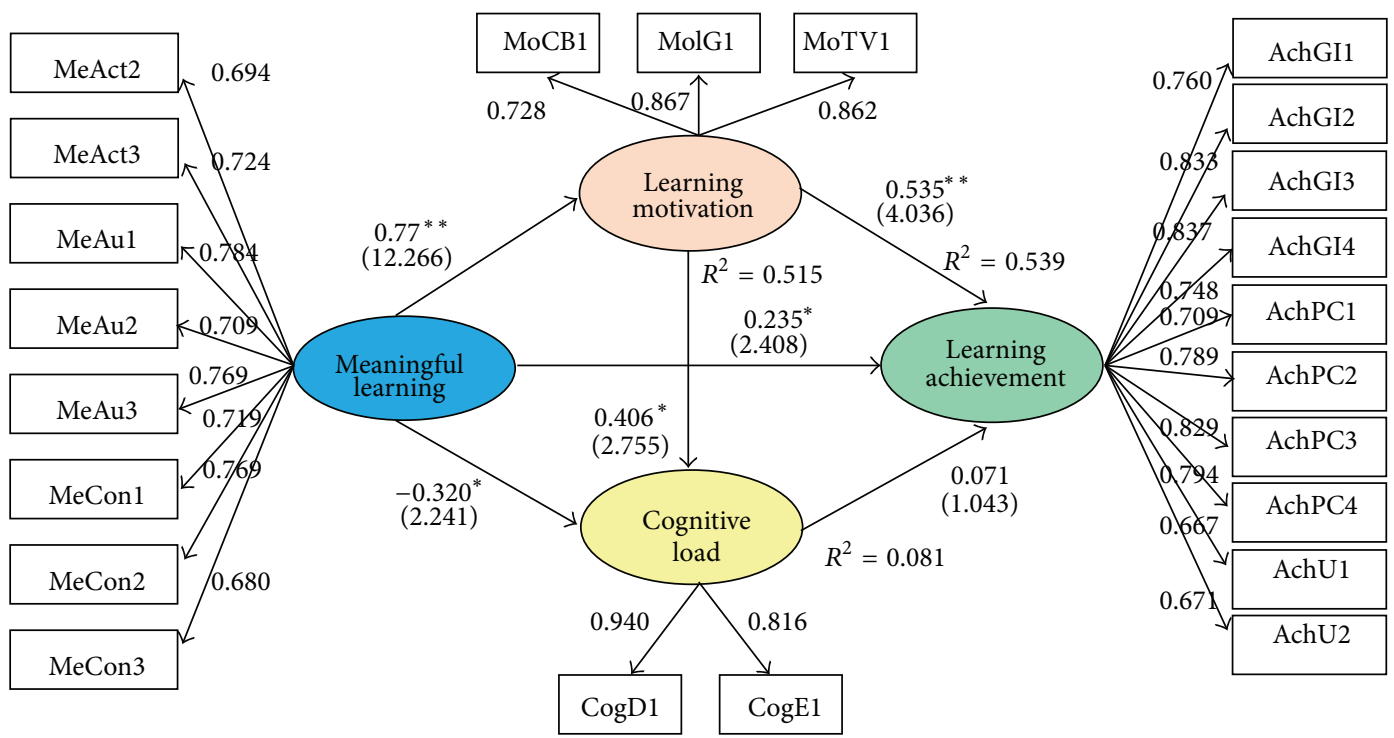

Figure 5: Path coefficient and regression in this research.

loads will not directly increase learning achievement. Hence, this point does not support the research results of Binet and Simon [32]; and Laidra et al. [33]

SPANI Subjects' Learning Motivation Has a Significantly Positive Relationship with the Degree of Cognitive Load Process Ability. The research results indicate that SPANI subjects have higher learning motivation towards teaching material. Moreover, their ability to handle the cognitive load when using SPANI increases. Therefore, SPANI subjects' increased learning motivation is useful to increase the ability to handle the cognitive load. This supports the findings of Schnotz [35].

Based on the results of this study, SPANI subjects consider that a cognitive load does not have a significant direct impact on learning achievement. Above we have mentioned, when discussing the system design, that we wanted users to be able to understand and learn how to absorb teaching content in an easy way. On this point, we suggest the subsequent research can conduct a more in-depth exploration of the users' cognitive load, which the digital content materials have given. For example, research could examine more about the cognitive load of digital teaching content and learning effects.

6.2. Implications. To make use of digital content materials is very useful for improving learning attitudes and for improving learning achievements.

In this research, SPANI subjects utilized meaningful learning strategies introduced in this project that were related to learning motivation, cognitive load, and learning achievements. All of our research hypotheses were confirmed. Hence, when using the learning strategies of meaningful learning properly, it can improve SPANI users' learning motivation, reduce the cognitive load, and enhance learning achievement. According to what was mentioned before, Maleki et al. [1] strongly recommended that making use of information and communication technology (ICT) in teaching can improve students' learning absorption and teaching quality. Certainly, the research results show that using ICT can increase SPANI users' learning motivation and decrease the cognitive load and increase teaching quality. In this research, the users' cognitive load was decreased with using the digital shooting posture correction materials SPANI which can help to improve deficiencies found in traditional curricula for courses related to teaching the correct basketball shooting posture. Moreover, it can increase the users' willingness to learn and motivation, which then increases the willingness of students to voluntarily practice at home.

Learning motivation affects the degree of the cognitive load and learning achievement.

In this study, SPANI subjects who have high motivation were able to handle a higher degree of cognitive loading and also had better performance on learning achievements. Moreover, the above supports the argument which was mentioned with respect to McClure et al's. [34] research. Their research was concerned with how the student's best or worst marks were related to achievement. His research found that learners' learning achievement decided how strong the learners' motivation was. In addition, using digital materials enhanced learners' interests so learners were less likely to feel bored during instruction, and this can further enhance motivation. Besides, the degree of the cognitive load is also related to the learners' motivation: stronger learning motivation leads to a decrease in the cognitive load. When the level of the ability to process cognitive load increases, learners can in turn learn more difficult concepts. Schnotz [35] indicated that learners' investment in learning activities is based on the intensity of their motivation, their attitude toward the subject, and their mental states. Our results supported the 
findings of Schnotz [35]. Consequently, we believe that enhancing learning motivation is one important component in designing a comprehensive teaching plan.

In this study, the above mentioned cognitive load did not have a negative influence on learning achievement. This result differs from other researchers' findings. Binet and Simon [32] referred to the use of the cognitive ability to predict learning achievement, and Laidra et al. [33] mentioned that academic achievement is based on the effect of cognitive ability. In this study, SPANI subjects' cognitive load had no significant influence on learning achievement for the following reasons.

(1) When I designed the interface and the program originally, I based it on design principles stating that users must be able to easily understand and operate the program. The design principles that users can easily understand or operate. The SPANI is referring to design interface of foreign Nature Interaction games as the primary reference.

(2) Before testers operate the system, they must be able to understand the purpose of the experiment, the content of the program, and the operating instructions of the system. Then, following the experiment, we collected feedback from our subjects. After the experiment, the system will obtain shooting posture grades from student, so student fully understood the contents of this experiment.

In this experiment, the result shows that the cognitive load does not directly affect academic achievement. The reasons could be the two points mentioned above. The highintensity motivation of learners, it can increase the degree of processing of cognitive load and learning achievements. We found that two of the important roles in teaching design are learning strategy and learning motivation.

\section{References}

[1] H. Maleki, A. Majidi, F. Haddadian, A. M. Rezai, and V. Alipour, "Effect of Applying Informant on and Communication Technology (ICT) on learning level and information literacy of students," Procedia, vol. 46, pp. 5862-5867, 2012.

[2] D. P. Ausubel and F. G. Robinson, School Learning: An Introduction to Educational Psychology, Holt, Rinehart and Winston, 1969.

[3] S. Kalyuga, P. Chandler, J. Tuovinen, and J. Sweller, "When problem solving is superior to studying worked examples," Journal of Educational Psychology, vol. 93, no. 3, pp. 579-588, 2001.

[4] P. R. Pintrich, D. Smith, T. Garcia, and W. J. McKeachie, A Manual for the Use of the Motivated Strategies for Learning Questionnaire, University of Michigan, Ann Arbor, Mich, USA, 1991.

[5] A. F. Cliff, "Teacher-learners' conceptions of learning: evidence of a "communalist" conception amongst postgraduate learners?" Higher Education, vol. 35, no. 2, pp. 205-220, 1998.

[6] N. Purdie and J. Hattie, "Assessing students' conceptions of learning," Australian Journal of Educational and Developmental Psychology, vol. 2, pp. 17-32, 2002.

[7] G. M. Boulton-Lewis, F. Marton, D. C. Lewis, and L. A. Wilss, "A longitudinal study of learning for a group of indigenous australian university students: dissonant conceptions and strategies," Higher Education, vol. 47, no. 1, pp. 91-112, 2004.
[8] M. Makoe, J. T. E. Richardson, and L. Price, "Conceptions of learning in adult students embarking on distance education," Higher Education, vol. 55, no. 3, pp. 303-320, 2008.

[9] D. Ausubel, The Psychology of Meaningful Verbal Learning: An Introduction to School Learning, Grune \& Stratton, New York, NY, USA, 1963.

[10] D. P. Ausubel, J. D. Novak, and H. Hanesian, Educational Psychology: A Cognitive View, Werbel \& Peck, New York, NY, USA, 1978.

[11] J. Sweller, Instructional Design in Technical Areas, ACER Press, Camberwell, Australia, 1999.

[12] E. Pollock, P. Chandler, and J. Sweller, "Assimilating complex information," Learning and Instruction, vol. 12, no. 1, pp. 61-86, 2002.

[13] P. Gerjets and K. Scheiter, "Goal configurations and processing strategies as moderators between instructional design and cognitive load: evidence from hypertext-based instruction," Educational Psychologist, vol. 38, no. 1, pp. 33-41, 2003.

[14] A. Renkl and R. K. Atkinson, "Structuring the transition from example study to problem solving in cognitive skill acquisition: a cognitive load perspective," Educational Psychologist, vol. 38, no. 1, pp. 15-22, 2003.

[15] M. Credé and L. A. Phillips, "A meta-analytic review of the Motivated Strategies for Learning Questionnaire," Learning and Individual Differences, vol. 21, no. 4, pp. 337-346, 2011.

[16] T. G. Duncan and W. J. McKeachie, "The making of the motivated strategies for learning questionnaire," Educational Psychologist, vol. 40, no. 2, pp. 117-128, 2005.

[17] R. Säljö, Learning in the Learner's Perspective: Some Commonsense Conceptions Issue 76 of Reports, Institute of Education, Gothenburg University, Gothenburg, Sweden, 1979.

[18] F. Marton, G. Dall'Alba, and E. Beatty, "Conceptions of learning," International Journal of Educational Research, vol. 19, pp. 277-300, 1993.

[19] J. Sweller, "Cognitive load during problem solving: effects on learning," Cognitive Science, vol. 12, no. 2, pp. 257-285, 1988.

[20] OpenNI, "OpenNI Unity software development kit (Unity SDK)," 2011, http://www.openni.org/Downloads/OpenNIModules.aspx.

[21] Ministry of Education, "High School Physical education and Information Technology teaching material," 2012, http://hsmaterial.moe.edu.tw/schema/pe/main.html.

[22] J. C. Nunnally, Psychometric Theory, McGraw-Hill, New York, NY, USA, 1978.

[23] C. Fornell and D. F. Larcker, "Evaluating structural equation models with unobservable variables and measurement error," Journal of Marketing Research, vol. 18, no. 1, pp. 36-50, 1981.

[24] R. P. Bagozzi and Y. Yi, "On the evaluation of structural equation models," Journal of the Academy of Marketing Science, vol. 16, no. 1, pp. 74-94, 1988.

[25] W. W. Chin and P. R. Newsted, "Structural equation modeling analysis with small samples using partial least squares," in Statistical Strategies for Small Sample Research, R. H. Hoyle, Ed., 1999.

[26] J. F. Hair, B. Black, B. Babin, R. E. Anderson, and R. L. Tatham, Multivariate Data Analysis, Macmillan, New York, NY, USA, 6th edition, 1992.

[27] I. B. Jum Nunnally, Psychometric Theory, McGraw-Hill Humanities, New York, 3rd edition, 1994. 
[28] J. Hulland, "Use of partial least squares (PLS) in strategic management research: a review of four recent studies," Strategic Management Journal, vol. 20, no. 2, pp. 195-204, 1999.

[29] P. A. Pavlou and M. Fygenson, "Understanding and predicting electronic commerce adoption: an extension of the theory of planned behavior," MIS Quarterly, vol. 30, no. 1, pp. 115-143, 2006.

[30] S. L. Chang and K. Ley, "A learning strategy to compensate for cognitive overload in online learning: learner use of printed online materials," Journal of Interactive Online Learning, vol. 5, no. 1, pp. 104-117, 2006.

[31] C. M. Michael Pressley, Advanced Educational Psychology for Educators, Researchers, and Policymakers, HarperCollins College Publishers, 1995.

[32] A. Binet and T. Simon, The Development of Intelligence in Children, Williams \& Wilkins, Baltimore, Md, USA, 1916.

[33] K. Laidra, H. Pullmann, and J. Allik, "Personality and intelligence as predictors of academic achievement: a cross-sectional study from elementary to secondary school," Personality and Individual Differences, vol. 42, no. 3, pp. 441-451, 2007.

[34] J. McClure, L. H. Meyer, J. Garisch, R. Fischer, K. F. Weir, and F. H. Walkey, "Students' attributions for their best and worst marks: do they relate to achievement?" Contemporary Educational Psychology, vol. 36, no. 2, pp. 71-81, 2011.

[35] W. Schnotz, "Reanalyzing the expertise reversal effect," Instructional Science, vol. 38, no. 3, pp. 315-323, 2010. 


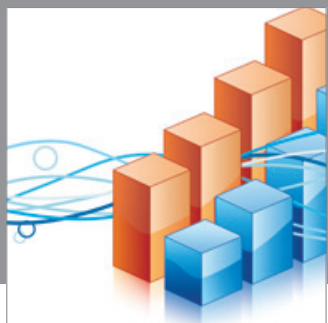

Advances in

Operations Research

mansans

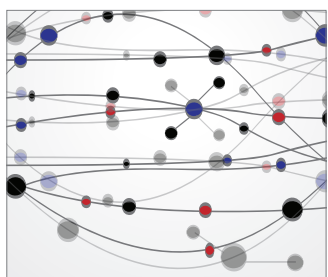

The Scientific World Journal
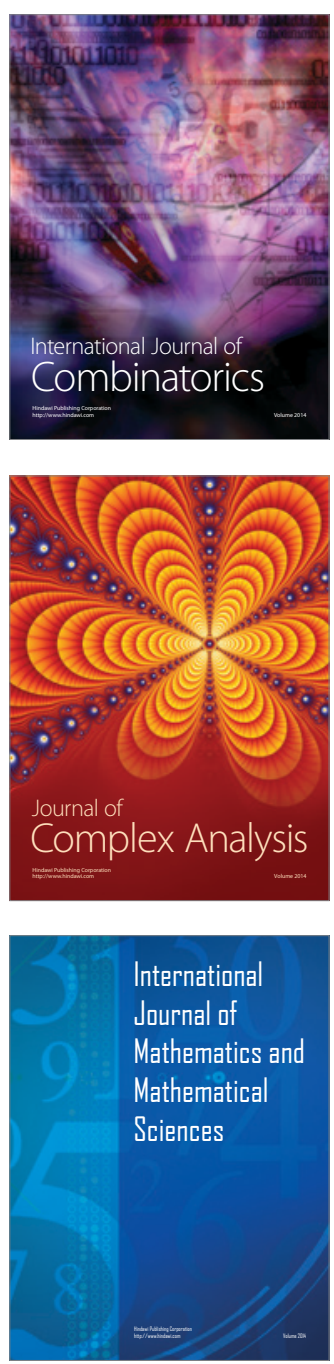
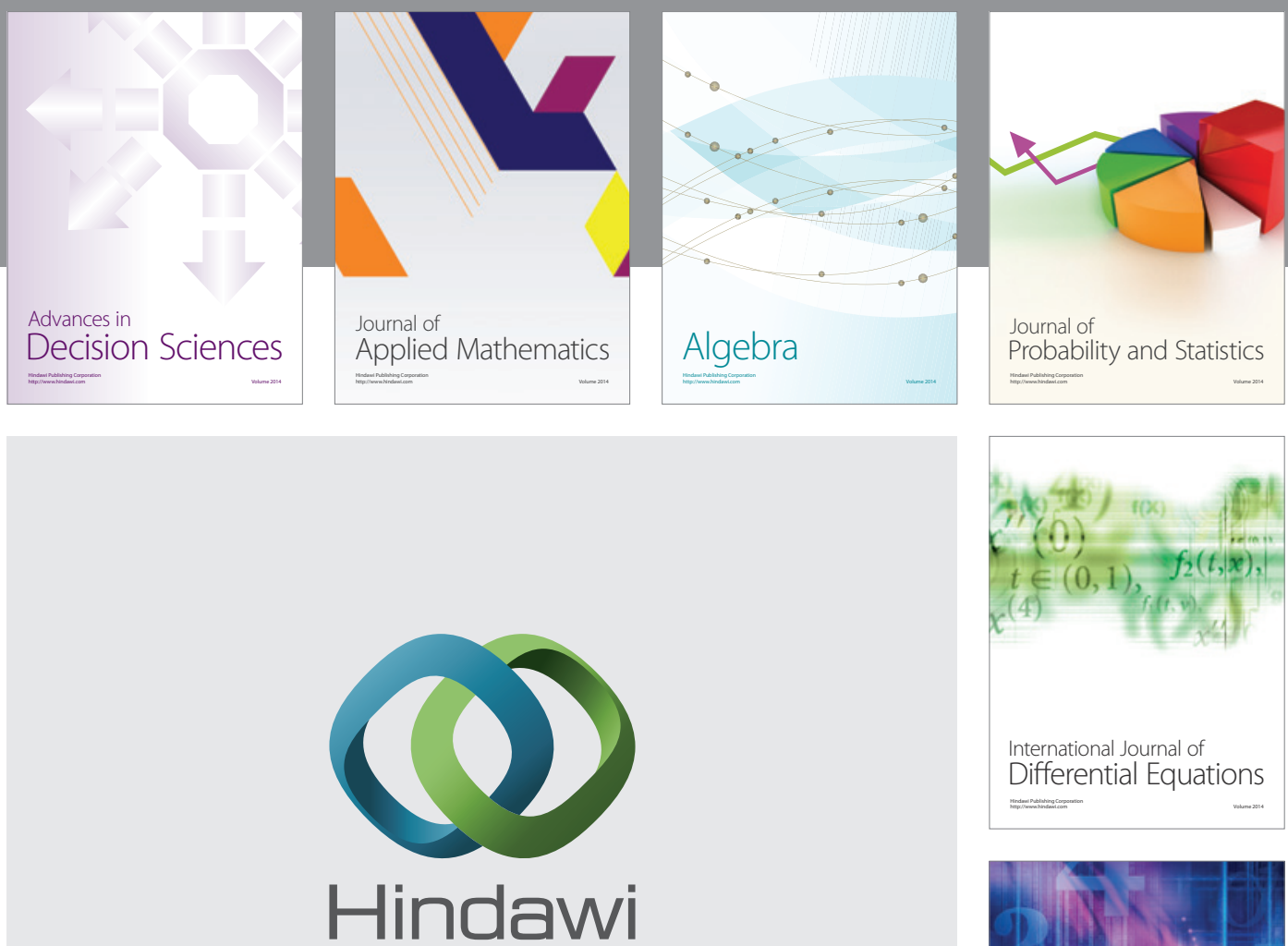

Submit your manuscripts at http://www.hindawi.com
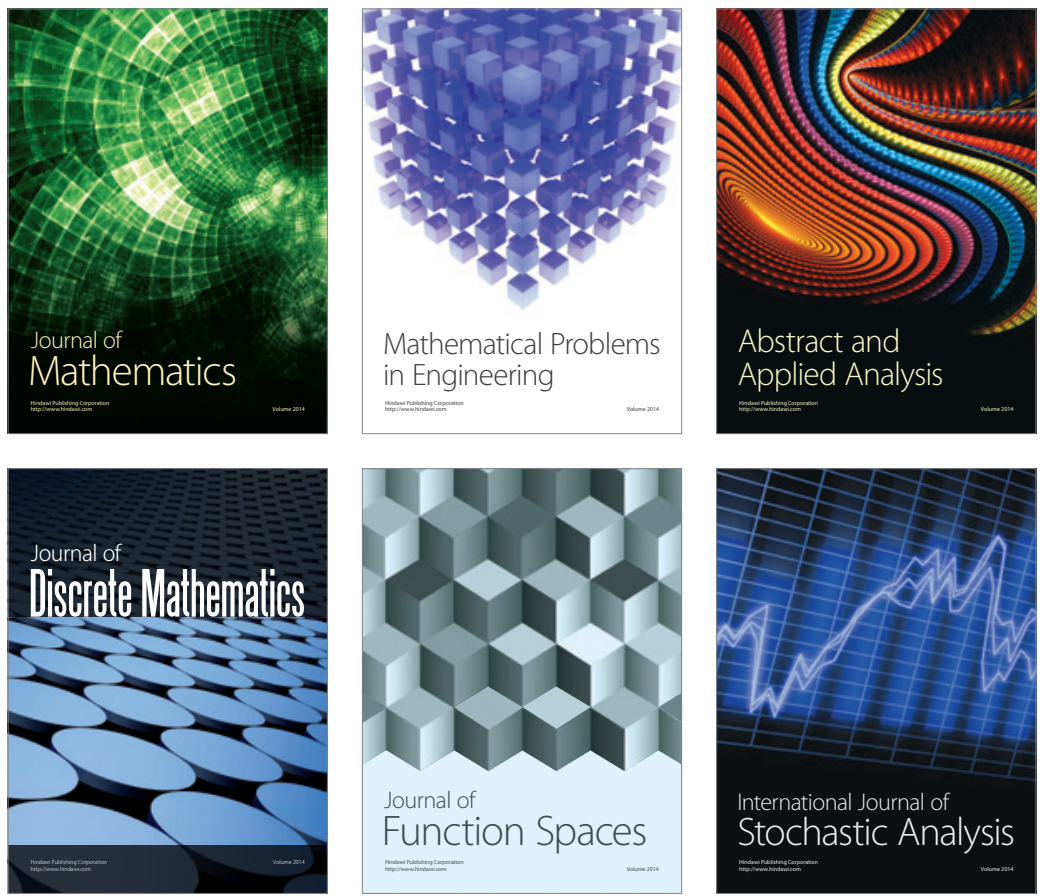

Journal of

Function Spaces

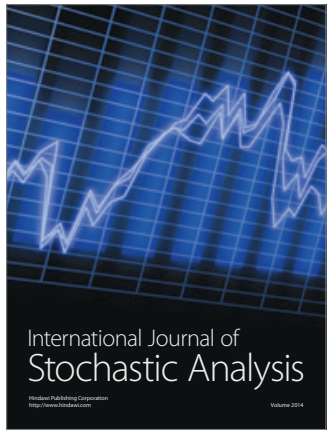

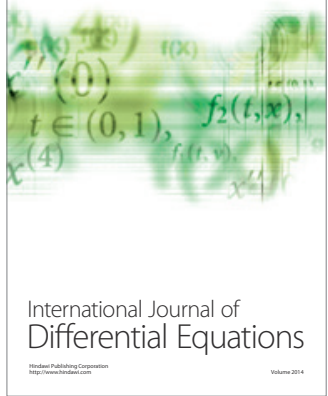
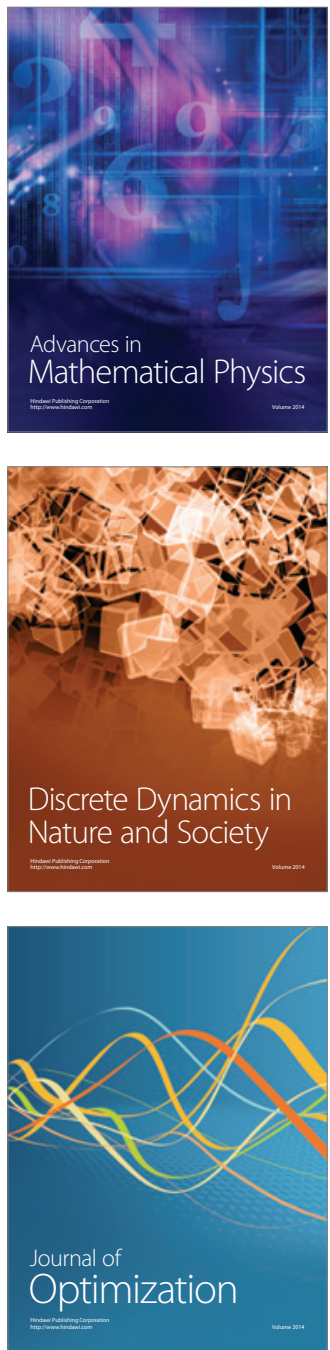